\title{
Unveiling the Insular Lobe of Reil: Neurophysiological and Anatomical Features
}

\section{Desvendando a ínsula de Reil: aspectos anatômicos e neurofisiológicos}

\author{
Daniel Damiani $^{1 \oplus}$ Ana Maria Nascimento ${ }^{1}$ Vanessa Gonçalves Pires ${ }^{1}$ \\ ${ }^{1}$ Department of Neuroscience, Universidade Anhembi Morumbi, São \\ Paulo, SP, Brazil \\ Address for correspondence Daniel Damiani, MD, Departamento de \\ Neurociência, Universidade Anhembi Morumbi, Sao Paulo, \\ Arq Bras Neurocir 2019;38:117-123. \\ SP 04705-000, Brazil (e-mail: damiani.neuroscience@gmail.com).
}

\begin{abstract}
Keywords

- insular lobe

- central core of the brain

- insular neurophysiology

- insular neurocircuitry

Resumo

Palavras-Chave

- lobo da ínsula

- bloco central do cérebro

- neurofisiologia da ínsula

- circuito da ínsula

The insular lobe has long been investigated, from its anatomical descriptions to its neurophysiological activity. Located in a central location, the insular lobe participates in several afferent and efferent pathways, forming part of the eloquent and fundamental structures that make up the central core of the brain. The lobe of the insula has participation in language function, such as speech, sensory (e.g., taste), limbic, autonomic (visceral), also forming part of complex associative circuits, including part of the circuits of mirror neurons. Several functional descriptions attributed to the insular lobe have been made in patients suffering from cerebrovascular diseases, as well as in those with epilepsy. Much progress and many descriptions have also been made in patients with tumors. Despite much information already available about the insular lobe, it is likely that much will be discovered in the coming years.

Há muito tempo já se investiga sobre o lobo da ínsula, desde suas descrições anatômicas até sua atividade neurofisiológica. Situado em localização estratégica, o lobo da ínsula participa de diversas vias aferentes e eferentes, fazendo parte das nobres e vitais estruturas que compõem o bloco central do cérebro. O lobo da ínsula possui participação nas atividades motoras voluntárias, tais como a fala, sensitivas (por exemplo, gustação), límbicas, autonômicas (viscerais), também fazendo parte de circuitos complexos associativos, incluindo parte dos circuitos dos neurônios-espelhos. Diversas descrições funcionais atribuídas ao lobo da ínsula são feitas em pacientes vítimas de acidentes vasculares encefálicos, de neoplasias, assim como em pacientes epilépticos. Apesar de muitas informações já disponíveis acerca do lobo da ínsula, muito ainda deve ser descoberto nos próximos anos.
\end{abstract}

\section{Introduction}

Described for the first time by Johann Christian Reil in $1796,{ }^{1}$ the insular lobe was considered "hidden" by several anato-

(1D) Daniel Damiani's ORCID is 0000-0001-5786-0923. mists and physiologists, earning this name for its Latin meaning: insula = island. Sometimes, it is completely hidden, surrounded by various brain lobes, including the frontal, the temporal, and the parietal operculum. Actually, it composes the most lateral part of the central core of the brain, which we will discuss later in the present paper. received

May 30, 2018

accepted

February 19, 2019
DOI https://doi.org/

10.1055/s-0039-1685153. ISSN 0103-5355.
Copyright (e 2019 by Thieme Revinter

Publicações Ltda, Rio de Janeiro, Brazil
License terms

(c) (1) $\ominus$ (5) 
Macroscopically, the lobe is composed of a central sulcus of the insula, dividing it into two long (posterior) gyri and three short (anterior) gyri, as well as an accessory gyrus in its most ventral portion, described by Brodmann in 1909. Currently, the concept of central core of the brain corresponds to several deep regions of the cerebral cortex, present in the two hemispheres, constituting a block between the brainstem and the cerebral cortex. The central core of the brain is composed of the insular surface (insular lobe), the basal ganglia, and the thalamus, thus connecting the brainstem to all of the supratentorial structures, including the extreme, external, and internal capsule. In this topography, the central core of the brain functions as a true station integrating the motor, sensorial, emotional and cognitive information. The understanding of the anatomy and of the physiology of the insula also includes its correlations with these other structures that compose the central core of the brain, elucidating a little more of its neurophysiology. ${ }^{2,3}$

According to studies performed on monkeys, the insular lobe receives afferents from the amygdaloid complex, from the dorsal thalamus, and from various regions of the cerebral lobes, particularly from the auditory areas of the parietal lobes. These afferents predominantly connect to the posterior portions of the insula, whereas the limbic afferents (the entorhinal, the perirhinal, and the posterior orbitofrontal cortexes) and cingulate gyrus connect with the anterior portions of the insular lobe. The anterior portions of the insula have reciprocal efferent pathways to the afferents; however, the same does not occur for the posterior portions of the insular lobe. Current knowledge of the human neurophysiology of the insular lobe is based on the clinical aspects observed in patients with epilepsy, tumors, and sequelae of cerebrovascular diseases that affect this region. Studies have shown that these patients often have a pattern of epilepsy that is extremely resistant to pharmacological treatment, with paresthesia (electric shock sensation, pharyngolaryngeal constriction), dysphonia, and dysarthria. In patients submitted to intraoperative cortical stimulation, stimuli to the anterior portions of the insula induced viscerosensitive symptoms (abdominal and thoracic discomfort as well as nausea), motor and somatosensitive, without specific topographic characteristics, only diffuse and nonspecific sensations. ${ }^{4,5}$ More recently, in addition to the symptoms mentioned above, there are descriptions of olfactory-gustatory responses, especially to the sensation of disgust. In general, the somatosensory responses were attributed to the posterior portions of the insular lobe, whereas the viscerosensitive responses were attributed to the anterior portions. Nguyen et al also report, but to a lesser extent, vestibular symptoms and aphasia in those patients with epilepsy refractory to medications. ${ }^{6}$ Pollatos et al describe, through neuroimaging, patients with autonomic symptoms, involving, among other things, changes in thermoregulation, also placing the insula in the center of homeostasis regulation. ${ }^{7}$

\section{Objectives}

The authors describe the insular lobe anatomically, highlighting the central core of the brain concept, with a functional correlation of this structure with other functional areas of the central nervous system.

\section{Methods}

Review article using the PubMed (National Institute of Health Database), SCIELO, LILACS and Cochrane databases as search tools. The keywords used were: insular lobe neurophysiology, insular lobe, insula of Reil, insular lobe neuroanatomy, central core, and insular lobe neurocircuitry. The most recent articles were selected, considering their citations and their respective impacts.

\section{Discussion}

\section{Central core of the brain}

The central core stands as a block on the top of the brainstem, at the morphological center of the supratentorial compartment. This solid block includes, from lateral to medial, the insular surface, the extreme capsule, the claustrum, the external capsule, the putamen, the globus pallidus, the internal capsule, the caudate nucleus, the stria terminalis, the septal region, and the thalamus. ${ }^{8}$ Also included in the concept of the central core is the medial portion of the anterior commissure and structures above and posterior to the anterior perforated substance, including the nucleus accumbens (ventral striatum), the Meynert basal nuclei, the ventral amygdalofugal pathways, and the innominate substance, corresponding to the ventral globus pallidus. Superiorly, the central core connects almost to the entire cerebral cortex through the cerebral isthmus and, inferiorly, through white projecting fibers that descend to the brainstem. There is no natural division between the central core and the brainstem. ${ }^{9}$

In the region of the cerebral isthmus, the white fibers arise from the central core radiating to all of the cerebral lobes. The isthmus is composed of the continuation of the extreme, of the external, and of the internal capsule, as well as of the extension of the anterior commissure and of the ventral amygdalofugal pathways. The cerebral isthmus is best visualized deep in the limiting sulci of the insula, where the fibers pass through a narrow space between the limiting sulci of the insula and the lateral ventricle cavity (-Fig. 1).

The insular surface is the most lateral portion of the central core, seen through the Sylvian fissure, removing the frontal, parietal and temporal operculum. The insular lobe is limited anteriorly, posteriorly and superiorly by the anterior, posterior and superior limiting sulci of the insula. 3,10,11 The third ventricle, the hypothalamus, and the epithalamus are grouped together in the midline, between the central cores of the left and right hemispheres. ${ }^{8}$

\section{Insular Lobe}

The insular surface is the most lateral part of the central core and is observed by splitting the sylvian fissure and retracting the frontotemporoparietal opercula. It is limited by the anterior, superior, and posterior insular limiting sulci (also referred to all together as the circular sulcus of 


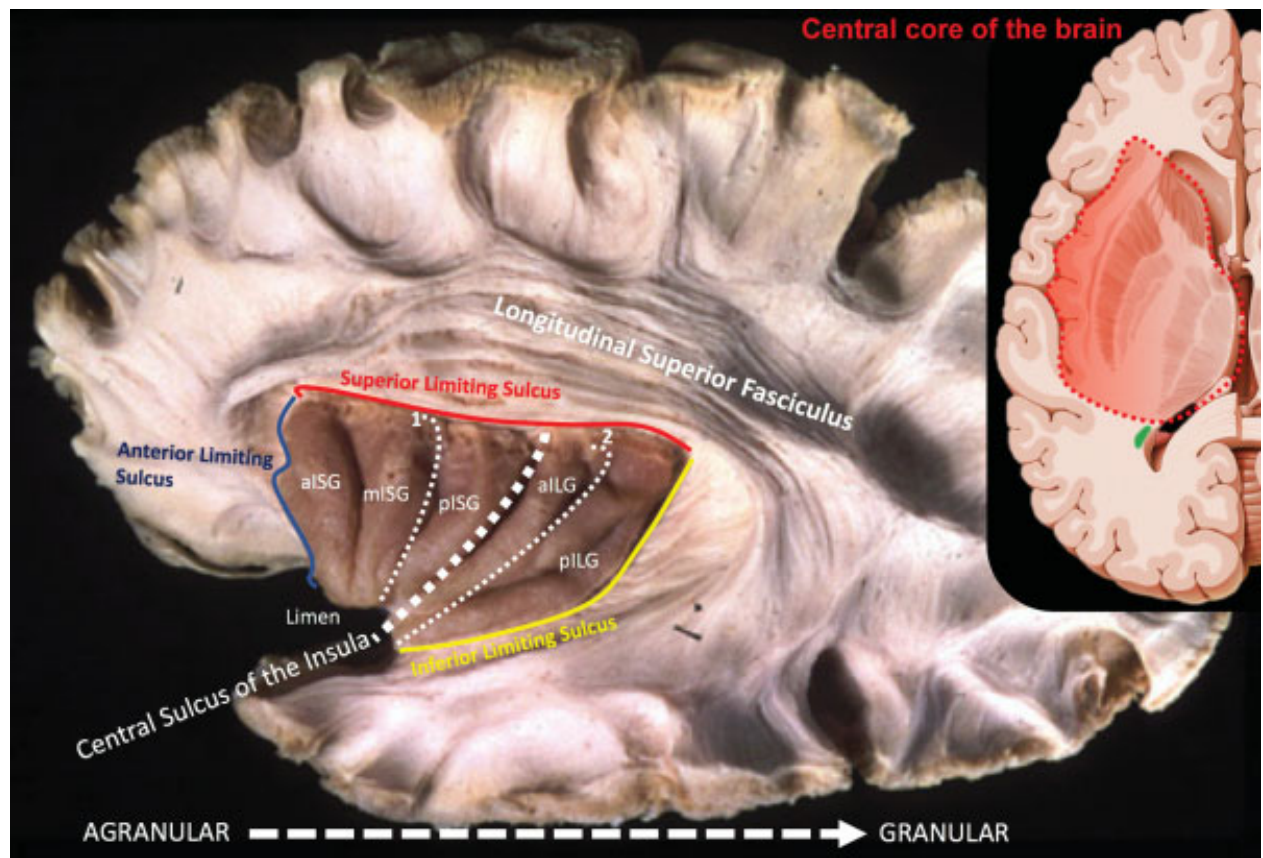

Fig. 1 Insular lobe anatomy, and the concept of central core of the brain, with neurological and neurosurgical relevance. 1. Precentral sulcus of the insula; 2. Postcentral sulcus of the insula. Abbreviations: alLG, anterior insular long gyrus; alSG, anterior insular short gyrus; mISG, middle insular short gyrus; pILG, posterior insular long gyrus; pISG, posterior insular short gyrus.

the insula). The limits of the central core were first defined by 3 planes, each drawn from one of the limiting sulci toward the lateral ventricle, marking the anterior, the superior, and the posteroinferior limits. Each of these planes passes through the cerebral isthmus, transecting the connections that link the central core to the other cerebral lobes. The insular surface is the most lateral aspect of the central core and is encircled by the insular limiting sulci. The limen insula is a hook-like structure found at the antero-inferior vertex of the insula and is connected to the anterior limiting sulci (ALS) and to the inferior limiting sulci (ILS). The point where the limen joins the ALS, at the frontal lobe, we refer to as the frontal limen point (FLP) and consider the beginning of the ALS. This sulcus ends at its meeting point with the superior limiting sulcus (SLS), which is referred to as the anterior insular point (AIP), which is also the superior anterior limit of the SLS. ${ }^{8,9,12}$ The central sulcus of the insula is visualized on the surface of the insular lobe, dividing the insular lobe into anterior and posterior areas. This sulcus is continuous and runs in the direction of the limen of the insula to the upper limiting sulcus of the insula. The anterior portion of the insula is composed of three short insular gyri most of the time. However, in some specimens, a fourth short gyrus or anterior accessory gyrus of the insula is found. A transverse gyrus of the insula is also present and communicates the anterior lower portion of the lobe with the posterior orbital gyrus and, in some cases, the accessory gyrus lies above this transverse gyrus, running along with the anterior limiting sulcus to the orbitofrontal operculum. The posterior portion of the insular lobe is composed of two long gyri, located posterior to the central sulcus of the insula. ${ }^{8}$

\section{Deep Structures}

After removing the cortical surface of the insular lobe, there will be exposure of the extreme capsule and, more medially, of the claustrum, consisting of a thin layer of gray matter present between the extreme and the external capsules, subdivided into the ventral and dorsal portion of the claustrum. The ventral claustrum runs the depth of the anteroinferior region of the insular surface, surrounded by white matter. Its continuation in the lower sense enters the amygdaloid complex. The dorsal claustrum is located superiorly and posteriorly, and its gray layer is organized in a thin and more compact form. ${ }^{3,10,11,13,14}$

\section{Insular Vasculature}

The insula receives its blood supply predominantly from the $\mathrm{M}_{2}$ (insular) segment of the middle cerebral artery. The middle cerebral artery, first running under the anterior perforated substance and sending lenticulostriate branches, reaches the limen insula and bends posteriorly over the insular surface. At the limen, or close to it, the middle cerebral artery bifurcates (or trifurcates) into trunks; the inferior trunk is frequently located along the ILS, while the superior one courses in a posterosuperior direction toward the SLS. These trunks, as well as their several main branches, send small arteries into the insular surface to supply its cortex. These small penetrating branches do not seem to reach too deep into the insular subcortical white matter, mostly stopping before the claustrum. The venous drainage of the insular region can be defined by cisternal drainage. The cisternal vessels are composed of the insular veins that drain the insular cortical surface and are directed to the limen insula, where they join the deep sylvian vein or the deep middle cerebral vein to later empty into the 
anterior part of the basal vein of Rosenthal. Occasionally, this group terminates at the sphenoparietal or cavernous sinuses. $^{8,12,14}$ It is well known that chronic hypertension induces pathological changes in cerebral vessels, resulting in either their occlusion or rupture, which leads to lacunar infarctions or intracerebral hemorrhages, respectively. Some striate arteriovenous malformations have been observed to receive their blood supply from these two groups of arteries: the middle cerebral artery $\left(\mathrm{M}_{2}\right.$ segment $)$ and the lateral lenticulostriate artery, which indicates the potential existence of microcommunicaton. ${ }^{12}$

\section{Functional Studies of the Insular Lobe}

The vast majority of information about insular functions comes from studies following cortical lesions (in animals and humans) or even through cortical electric stimulation. Since the first studies performed by Penfield in 1955, with electric corticostimulation, the insular surface seems to provide visceroception and somatosensory symptoms (- Figs. 2 and 3 ).

\section{Thermoception and Nociception}

Painful stimuli appear to be triggered by electrical stimuli in the posterosuperior portion of the insular lobe, predominantly in the right hemisphere. In the most posterosuperior portions, the presence of the thermoception associated with somatosensitivity is described. The somatotopic distribution of sensitivity is as follows: upper limbs in the dorsal part, while lower limbs are more ventral. The facial sensitivity is also found in the more ventral portions. ${ }^{2,15,16}$ The anterior and lateral spinothalamic pathway, after projecting to the thalamus (posterior ventromedial nucleus), is directed to the postcentral gyrus, and some fibers, such as the spinoreticular pathway (positioned closely to the lateral spinothalamic tract), pass through the posterior cortical surface of the insula and the cingulum after connections to the medullary laminae of the thalamus. The anterior and lateral spinotha- lamic tract is an important projection of the main somatosensory pathway (protopathic touch, nociception, and thermoception), thus differentiating itself from the dorsal column lemniscal pathways responsible for the epicritic and vibratory sensitivity. ${ }^{16}$

\section{Somatosensitivity}

Since 1955, Penfield and Faulk have associated somatosensitivity to the insular lobe. Currently, with functional neuroimaging studies, Eickhoff et al, using studies on cerebral cytoarchitecture, question the actual existence of a specific insular somatosensory area, proposing that this region would consist only of the extension of the parietal operculum (post-central gyrus). ${ }^{17,18}$ In a postmortem study in 10 human specimens, Kurth et al separated three cytoarchitectonically distinct area regions in the posterior insular lobe: two granular cortical regions in the posterior dorsal insula, called $\operatorname{Ig} 1$ and $\operatorname{Ig} 2$, respectively, and a dysgranular cortical area, named Idg1, located in the ventral posterior insula, associated with a great variety of cortical somatosensory electrical stimuli. The presence of the granular cortex is predominantly associated with afferent fibers, associating with somatosensitivity, thermosensitivity, and nociception. Projections of these granular and dysgranular cortices are observed and come from the limbic areas, including the amygdaloid complex and the entorhinal cortex, suggesting the presence of an important limbic-cortical connection in this location, which is associated with motor learning and with the mechanisms of memory consolidation. Thus, the regions of the granular insular cortex represent secondary somatosensory and tertiary areas. ${ }^{5}$ Kahane et al $^{19}$ describe vestibular phenomena associated with electrical stimuli of the posterior insula, such as dizziness, nausea, vomiting and vertigo. The posterior dorsal region of the insula receives thalamic afferents (upper and lower posterior ventral nuclei of the thalamus), projecting into the parietal insular vestibular cortex, justifying these symptoms. $^{19}$

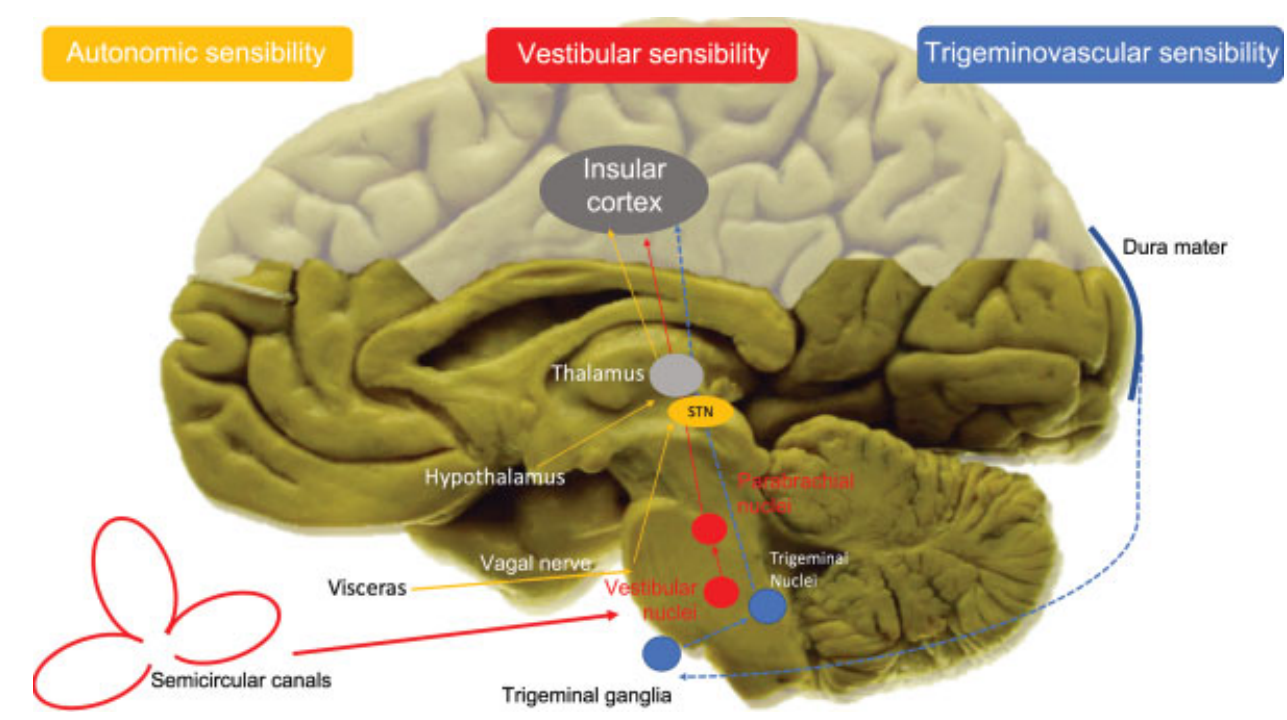

Fig. 2 Some afferent pathways related to the insular lobe. The three main systems that deserve attention: autonomic sensitivity pathways; trigeminal sensitivity, and vestibular sensitivity pathways. Abbreviation: STN, solitary tract nucleus. Modified from Borsook D et al. ${ }^{22}$ 


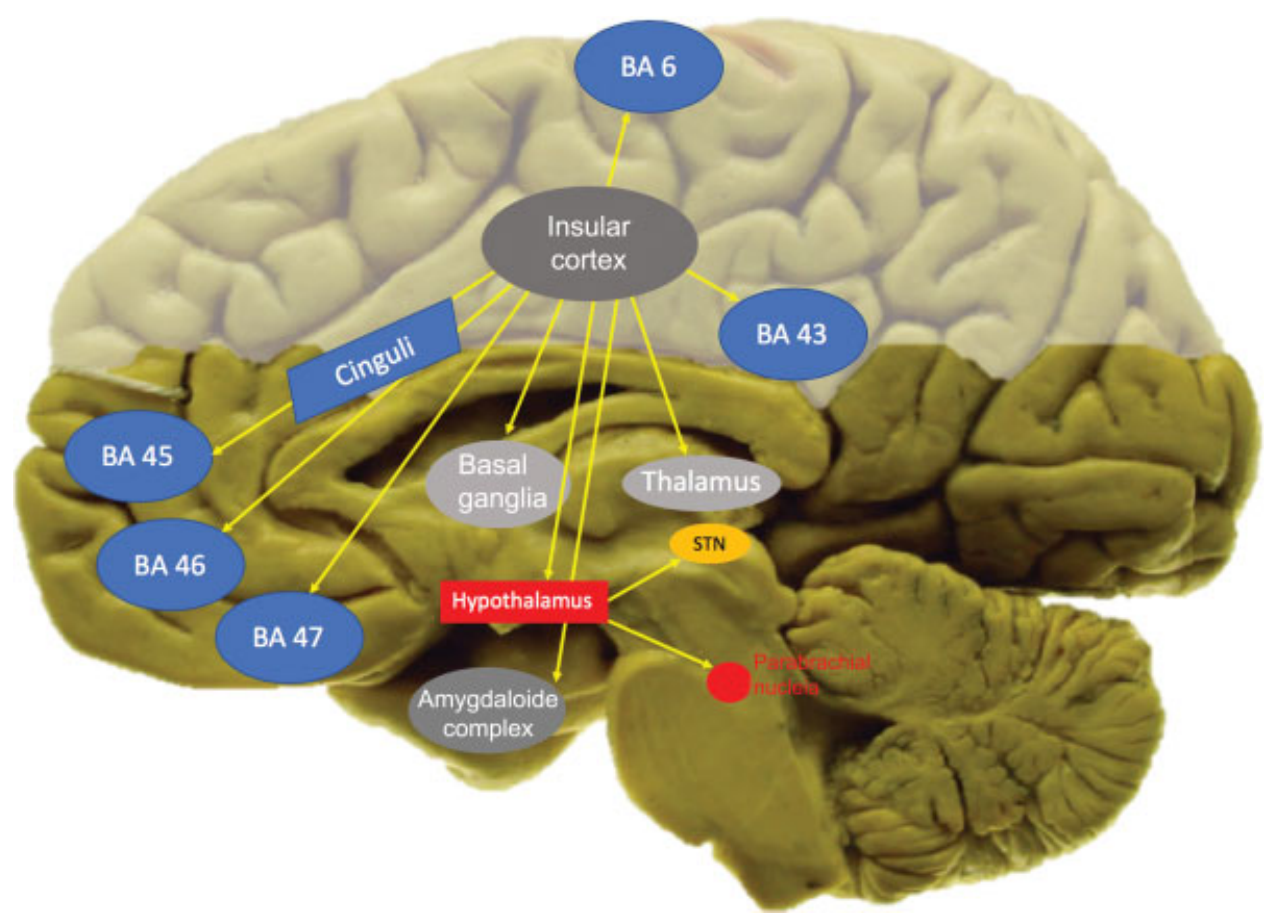

Fig. 3 Some efferent pathways related to the insular lobe. Abbreviations: BA, Brodmann Area; STN, solitary tract nucleus. Modified from Borsook D et al. ${ }^{22}$

\section{Visceroception}

Visceral symptoms are extremely relevant when electrically stimulating the insular cortex. Some authors further propose that the ventral insula could be an extension of the gustatory cortex. Stimuli to these regions give rise to gastrointestinal motor activity, transmitted by vagal nerves bilaterally; once both vague nerves have been damaged, complete suppression of insular gastrointestinal motility control is observed. In addition, the gastrointestinal afferent pathways ascend to the thalamus (medial and parvocellular ventroposterior nuclei), projecting to the granular and dysgranular cortices. Functional neuroimaging studies revealed that after feeding, healthy volunteers had increased metabolic activity in their cortexes. Ischemic insular lesions in the regions attributed to visceroception commonly occur with dysphagia alone, producing evidence for the hypothesis that the solitary tract nucleus (vagal afferent) protrudes mainly to the insular cortex. ${ }^{2,19,20}$

\section{Taste}

The gustatory pathway begins in the chord tympani nerve projecting from the solitary tract nucleus (STN), located in the brainstem, to the hypothalamus and to the ventromedial parvocellular nucleus of the thalamus. It is anatomically accepted that the gustatory area is not part of the primary somatosensitive cortex, where the tongue is included. Taste appears to be situated in the central portion of the insula (being more posterior in humans compared with primates, for example), receiving ventromedial thalamic afferences as well as afferent frontal and parietal operculum. ${ }^{21}$ Epileptic seizures involving these regions of the insula commonly occur with unpleasant sensations involving taste, often described as a "disgust" sensation, also associated with facial expression. However, insular lesions cause gustatory phenomena in the ipsilateral hemitongue to the injured cortex; however, complete deficits (in both hemitongues), with an inability to recognize the food, can be triggered by involvement of the left insular lobe. ${ }^{2}$

\section{Anterior Part of the Insular Lobe}

Initially, we must consider that the central sulcus of the insula does not divide it functionally, only anatomically. The central sulcus of the insula does not coincide with microscopic alterations that justify its functional modification. ${ }^{22}$ In animals, the anterior agranular insula seems to have relevant connections with the limbic and paralimbic cortexes, especially the connections between the anterior insula and the cingulate gyrus. However, Craig et $\mathrm{al}^{23}$ propose that the anterior insula would participate in important integrative functions related to self-recognition or interoception ("self-circuit," like a neural map of body states), attention, emotion, subjective sensations such as joy, sadness, pleasure, and pain beyond their own perception. The anterior part of the insular lobe also seems to be able to codify pleasurable behaviors, justified by their connections to the nucleus accumbens, as part of the reward circuitry. ${ }^{1}$ In general, the anterior portion of the insula can be considered as an associative area between homeostatic functions (including autonomic control) and emotional processing. ${ }^{23}$ Disconnections between the brainstem and the cortex of the anterior insula, or even between the anterior insula and the claustrum, can severely compromise the level of consciousness. ${ }^{24}$ Atypical cytoarchitectural presentations of the anterior insula are observed in individuals diagnosed with autism spectrum disorder (ASD), thus showing the importance 
of this anterior region also in social interaction. ${ }^{25}$ Thus, the empathy circuit was attributed to the connections between the anterior insula and the medial portion of the cingulate gyrus: individuals considered as being more empathic have a higher density of neurons in this circuit, whereas individuals with ASD, for example, have a marked reduction in the cellularity of this region. ${ }^{15}$

\section{Social Behavior and Mirror-neurons Circuit}

Empathy is defined as the ability to understand the other, associated with visceral emotional reactions, correlated to the various situations in which the other is living; it is literally the situation of understanding another person by putting oneself in the "skin of the other." Trying to understand the neural circuitry correlated to empathy, Rizzolatti et al described in 1992 the circuit of mirror-neurons, initially observing primates. Rizzolatti et al reported that when they visualized motor acts performed by their peers, monkeys activated brain circuits, as if they were performing the motor act themselves. Besides the motor aspect, this neurocircuit brought to the neurosciences the idea that socialization depends on one's own perception of the situation of the other, being able to put oneself in the place of the other. This circuit has great activation only in the fact of imagining the pain that the other could be feeling, anticipating it only by imagination itself. ${ }^{26,27}$ As already mentioned, the insula is strategically located in a region where it facilitates the interconnection between the limbic system and the thalamus. The bodily representation itself, that is, the "selfcircuit", is present in the insula, including unpleasant sensations like disgust. The circuits of mirror-neurons also have associative areas in the insular lobe, being intensely activated at the moment of imitation of a movement only initially visualized. Singer et al observed that personally experienced pain sensation activates the insular lobe, as well as the observation of someone experiencing the painful sensation, with only the imagination of the pain sensation. ${ }^{28,29}$

\section{Clinical Aspects Related to the Insular Lobe}

Several neurological and psychiatric diseases present involvement of the insular lobe, given its behavioral, motivational and cognitive functions. Patients with depression, anxiety and schizophrenia have a significant reduction of gray matter present in the insular lobe. Psychopathy and eating disorders such as anorexia (autoimage disorder) also find correlation with functional insular abnormalities. In neurology, the involvement of facial expression of emotions can be found in Huntington chorea and in multiple sclerosis, whereas in Alzheimer dementia, the impairment of the "self-circuit" becomes more evident. ${ }^{1}$ Neuroimaging studies associate dysfunctions of the insular cortex with motivational deficits, as well as with the behavior of addiction. Substance abuse appears to directly activate the insular cortex, thereby modulating its behavioral aspect involved in the reward circuit. Injuries in these regions often occur with anhedonia. ${ }^{30} \mathrm{Cur}$ rently, transcranial magnetic stimulation has been performed and maybe will reveal new aspects of the insular neurophysiology. ${ }^{31,32}$

\section{Conclusions}

Topographically located in a strategic position, the insular lobe has several interactions with sensorial modalities, integrating the limbic system to the somatosensitive and the motor systems. Definitely, the anterior insula can be considered an area of tertiary association, participating in a coupled way in the interpretation of information and decision-making, together with the parieto-occipitotemporal areas, the limbic association area, and the prefrontal area (ventromedial, dorsolateral and orbitofrontal). Ischemia affecting the insular lobe may mimic lacunar infarcts, affecting purely motor or sensory functions, often involving functional areas of language, which, when associated with vertigo, nausea, taste disorders and auditory processing, speak strongly in favor of lesions of the insular lobe. $^{32}$

\section{Conflicts of Interests}

The authors have no conflicts of interests to declare.

\section{References}

1 Namkung H, Kim SH, Sawa A. The insula: An underestimated brain area in clinical neuroscience psychiatry, and neurology. Trends Neurosci 2017;40(04):200-207

2 Stephani C, Fernandez-Baca Vaca G, Maciunas R, Koubeissi M, Lüders HO. Functional neuroanatomy of the insular lobe. Brain Struct Funct 2011;216(02):137-149

3 Ribas EC, Yagmurlu K, Wen HT, Rhoton AL Jr. Microsurgical anatomy of the inferior limiting insular sulcus and the temporal stem. J Neurosurg 2015;122(06):1263-1273

4 Isnard J, Guénot M, Sindou M, Mauguière F. Clinical manifestations of insular lobe seizures: a stereo-electroencephalographic study. Epilepsia 2004;45(09):1079-1090

5 Kurth F, Eickhoff SB, Schleicher A, Hoemke L, Zilles K, Amunts K. Cytoarchitecture and probabilistic maps of the human posterior insular cortex. Cereb Cortex 2010;20(06):1448-1461

6 Nguyen DK, Nguyen DB, Malak R, et al. Revisiting the role of the insula in refractory partial epilepsy. Epilepsia 2009;50(03): 510-520

7 Pollatos O, Schandry R, Auer DP, Kaufmann C. Brain structures mediating cardiovascular arousal and interoceptive awareness. Brain Res 2007;1141:178-187

8 Ribas EC, Yağmurlu K, de Oliveira E, Ribas GC, Rhoton A. Microsurgical anatomy of the central core of the brain. J Neurosurg 2018;129(03):752-769

9 Türe U, Yaşargil DC, Al-Mefty O, Yaşargil MG. Topographic anatomy of the insular region. J Neurosurg 1999;90(04):720-733

10 Rhoton AL Jr. The lateral and third ventricles. Neurosurgery 2002; 51(4, Suppl)S207-S271

11 Rhoton AL Jr. The cerebrum. Neurosurgery 2002;51(4, Suppl) S1-S51

12 Türe U, Yaşargil MG, Al-Mefty O, Yaşargil DC. Arteries of the insula. J Neurosurg 2000;92(04):676-687

13 Ribas GC, Oliveira Ed. [The insula and the central core concept]. Arq Neuropsiquiatr 2007;65(01):92-100

14 Choi CY, Han SR, Yee GT, Lee CH. Central core of the cerebrum. J Neurosurg 2011;114(02):463-469

15 Small DM. Taste representation in the human insula. Brain Struct Funct 2010;214(5-6):551-561

16 Tanriover N, Rhoton AL Jr, Kawashima M, Ulm AJ, Yasuda A. Microsurgical anatomy of the insula and the sylvian fissure. J Neurosurg 2004;100(05):891-922 
17 Mazzola L, Isnard J, Peyron R, Guénot $\mathrm{M}$, Mauguière F. Somatotopic organization of pain responses to direct electrical stimulation of the human insular cortex. Pain 2009;146(12):99-104

18 Eickhoff SB, Schleicher A, Zilles K, Amunts K. The human parietal operculum. I. Cytoarchitectonic mapping of subdivisions. Cereb Cortex 2006;16(02):254-267

19 Kahane P, Hoffmann D, Minotti L, Berthoz A. Reappraisal of the human vestibular cortex by cortical electrical stimulation study. Ann Neurol 2003;54(05):615-624

20 Ladabaum U, Roberts TP, McGonigle DJ. Gastric fundic distension activates fronto-limbic structures but not primary somatosensory cortex: a functional magnetic resonance imaging study. Neuroimage 2007;34(02):724-732

21 Riecker A, Gastl R, Kühnlein P, Kassubek J, Prosiegel M. Dysphagia due to unilateral infarction in the vascular territory of the anterior insula. Dysphagia 2009;24(01):114-118

22 Borsook D, Veggeberg R, Erpelding N, et al. The insula: 'a hub of activit' in migraine. Neuroscientist 2016;22(06):632-652

23 Craig AD. How do you feel-now? The anterior insula and human awareness. Nat Rev Neurosci 2009;10(01):59-70

24 Fischer DB, Boes AD, Demertzi A, et al. A human brain network derived from coma-causing brainstem lesions. Neurology 2016; 87(23):2427-2434
25 Odriozola P, Uddin LQ Lynch CJ, Kochalka J, Chen T, Menon V. Insula response and connectivity during social and non-social attention in children with autism. Soc Cogn Affect Neurosci 2016;11(03):433-444

26 Rizzolatti G, Craighero L. The mirror-neuron system. Annu Rev Neurosci 2004;27:169-192

27 Shirtcliff EA, Vitacco MJ, Graf AR, Gostisha AJ, Merz JL, ZahnWaxler C. Neurobiology of empathy and callousness: implications for the development of antisocial behavior. Behav Sci Law 2009;27 (02):137-171

28 Singer T. The neuronal basis and ontogeny of empathy and mind reading: review of literature and implications for future research. Neurosci Biobehav Rev 2006;30(06):855-863

29 Singer T, Seymour B, O'Doherty J, Kaube H, Dolan RJ, Frith CD. Empathy for pain involves the affective but not sensory components of pain. Science 2004;303(5661):1157-1162

30 Treadway MT, Zald DH. Parsing anhedonia: translational models of reward-processing deficits in psychopathology. Curr Dir Psychol Sci 2013;22(03):244-249

31 Dayan E, Censor N, Buch ER, Sandrini M, Cohen LG. Noninvasive brain stimulation: from physiology to network dynamics and back. Nat Neurosci 2013;16(07):838-844

32 Lemieux F, Lanthier S, Chevrier MC, et al. Insular ischemic stroke: clinical presentation and outcome. Cerebrovasc Dis Extra 2012;2 (01):80-87 